\title{
Prevalence of Depression among 8-17 Years of Age Attending OPD at a Tertiary Care Hospital
}

\author{
Vedapriya Abimannan ${ }^{1}$. Sriram Pothapregada ${ }^{2}$. Balachandar Bangalore Varadhan ${ }^{1}$. \\ Shanmuga Vadivu Abimannan ${ }^{3} \cdot$ Ruth Ann Mathew ${ }^{2}$
}

Received: 2 January 2021 / Accepted: 27 April 2021 / Published online: 10 June 2021

(C) Dr. K C Chaudhuri Foundation 2021

To the Editor: Depression in children and adolescents has been increasing worldwide and despite its high prevalence and its substantial global impact, the detection and its treatment in primary care setting have been suboptimal [1]. It can have a significant adverse effect on a youth's emotional, social, and cognitive development. Its occurrence at an early age increases the risk of substance abuse, suicide attempts, impairment in relationships, recurrent depressive episodes, educational underachievement, and poor quality of life [2]. We did a cross-sectional study after ethical committee approval among 400 participants 8 to $17 \mathrm{y}$ of age presenting to the outpatient department in our hospital. A three-step process on diagnosis was involved. Step 1: Screening for psychiatric and behavioral morbidities using standardized Strengths and Difficulties Questionnaire [3]. Step 2: Those scoring $>19$ were subjected to a screening test for depression using Center for Epidemiological Studies Depression Scale for Children by interview method and an individual scoring above 15 was diagnosed to have depression. Step 3: All those participants were referred for psychiatric assessment and counseling. We found that $49(12.25 \%)$ participants had

Sriram Pothapregada

psriram_ped@yahoo.co.in

1 Department of Pediatrics, Rajiv Gandhi Government Women \& Children Hospital, Puducherry, India

2 Department of Pediatrics, Indira Gandhi Medical College \& Research Institute, Puducherry 605009, India

3 Department of Psychiatry, Government Hospital Kavindapadi, Erode, Tamil Nadu, India depression and among them, $10(5 \%)$ were in the age group of 8 to $12 \mathrm{y}$ and $39(19.5 \%)$ were in the age group of 13 to $17 \mathrm{y}$, which was similar to previous studies [1-4]. The mean age was $12.4 \pm 2.9 \mathrm{y}$. The male to female ratio was 1.2:1. The risk factors significantly associated with depression were age group $>12 \mathrm{y}$, peer group, sickness, bullying, constant fidgeting, temper tantrum, and addiction among parents. However, it has limited applicability to general population, as the study population was tertiary care hospital OPD setting and a wider community-based study would be ideal. Mental health is of paramount importance and emphasis should be on early diagnosis and management, especially in children and adolescents.

\section{Declaration}

Conflict of Interest None.

\section{References}

1. Jayashree K, Mithra PP, Nair MKC, Unnikrishnan B, Pai K. Depression and anxiety disorders among Schoolgoing adolescents in an urban area of South India. Indian J Community Med. 2018;43(Suppl 1):S28-32.

2. Singh K, Junnarkar M, Sharma S. Anxiety, stress, depression, and psychosocial functioning of Indian adolescents. Indian J Psychiatry. 2015;57:367-74.

3. Goodman R. The strengths and difficulties questionnaire: a research note. J Child Psychol Psychiatry. 1997;38:581-6.

4. Stockings E, Degenhardt L, Lee YY, et al. Symptom screening scales for detecting major depressive disorder in children and adolescents: a systematic review and meta-analysis of reliability, validity and diagnostic utility. J Affect Disord. 2015;174:447-63.

Publisher's Note Springer Nature remains neutral with regard to jurisdictional claims in published maps and institutional affiliations. 